\title{
Withdrawal of infliximab therapy in ankylosing spondylitis in persistent clinical remission, results from the REMINEA study
}

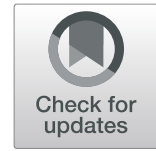

\author{
Mireia Moreno ${ }^{1}$, Jordi Gratacós ${ }^{1 *}$, Vicenç Torrente-Segarra², Raimon Sanmarti ${ }^{3}$, Rosa Morlà ${ }^{4}$, Caridad Pontes ${ }^{5}$, \\ Maria Llop ${ }^{1}$, Xavier Juanola ${ }^{6}$ and REMINEA study Group
}

\begin{abstract}
Background: Recent data suggest that anti-TNF doses can be reduced in ankylosing spondylitis (AS) patients. Some authors even propose withdrawing treatment in patients in clinical remission; however, at present there is no evidence to support this.

Objective: To assess how long AS patients with persistent clinical remission remained free of flares after anti-TNF withdrawal and to evaluate the effects of treatment reintroduction. We also analyze the characteristics of patients who did not present clinical relapse.

Methods: Multicenter, prospective, observational study of a cohort of patients with active AS who had received infliximab as a first anti-TNF treatment and who presented persistent remission (more than 6 months). We recorded at baseline and every 6-8 weeks over the 12-month period the age, gender, disease duration, peripheral arthritis or enthesitis, HLA-B27 status, BASDAI, CRP, ESR, BASFl, and three visual analogue scales, spine global pain, spinal night time pain, and patient's global assessment.

Results: Thirty-six out of 107 patients (34\%) presented persistent remission and were included in our study. After treatment withdrawal, 21 of these 36 patients (58\%) presented clinical relapse during follow-up. Infliximab therapy was reintroduced and only 52\% achieved clinical remission, as they had before the discontinuation of infliximab; in an additional 10\%, reintroduction of infliximab was ineffective, obliging us to change the anti-TNF therapy. No clinical or biological factors were associated with the occurrence of relapse during the follow-up.
\end{abstract}

Conclusions: Two thirds of patients in clinical remission presented clinical relapse shortly after infliximab withdrawal. Although the reintroduction of infliximab treatment was safe, half of the patients did not present the same clinical response that they had achieved prior to treatment withdrawal.

Keywords: Ankylosing spondylitis, Anti-TNF therapy, Disease activity, Treatment withdrawal

\section{Background}

Axial spondyloarthritis (axSpA) comprises a group of chronic, immune-mediated inflammatory diseases characterized by the predominance of inflammation in the sacroiliac joints and spine. Involvement of peripheral skeletal sites and extra-articular manifestations, such as uveitis, psoriasis, or inflammatory bowel disease (IBD), may develop during the course of the disease [1].

\footnotetext{
*Correspondence: jgratacosmas@gmail.com

'Rheumatology Department, Parc Taulí Hospital Universitari, I3PT, Universitat

Autònoma de Barcelona, 08208 Sabadell, Barcelona, Spain

Full list of author information is available at the end of the article
}

Ankylosing spondylitis (AS) is the most representative disease in this group; its burden has recently been recognized as severe, frequently leading to invalidity, work loss, and social impairment $[1,2]$.

The introduction of biological therapy has undoubtedly been an important step forward in improving the quality of life, activity, functionality, metrology, and most extra-articular manifestations in patients with AS and other forms of spondyloarthropathy [1]. Around $60 \%$ of patients treated with an anti-TNF achieve a good clinical response; however, according to the Assessment of Spondyloarthritis International Society (ASAS), only 20

(c) The Author(s). 2019 Open Access This article is distributed under the terms of the Creative Commons Attribution 4.0 International License (http://creativecommons.org/licenses/by/4.0/), which permits unrestricted use, distribution, and 
$30 \%$ achieve criteria of clinical partial remission in which the patient is apparently asymptomatic $[3,4]$.

Data from uncontrolled studies and from clinical practice support the possibility of reducing anti-TNF doses below the normal levels licensed in AS patients with good clinical response, and especially in patients in clinical remission [5-7]. In this sense, a recent consensus paper from the Spanish Society of Rheumatology and the Spanish Society of Hospital Pharmacy [8] stressed the possibility of withdrawing anti-TNF treatment in some patients who maintain good clinical response after intensive reduction of anti-TNF treatment [8], but the evidence supporting this recommendation is lacking.

In this sense, previous classic studies have suggested the need to maintain anti-TNF therapy indefinitely, as the withdrawal of this treatment is associated with disease reactivation in around $90 \%$ of patients within 12 months, independently of the anti-TNF used or the previous duration of treatment [9]. The factors associated with these reactivations include the high clinical activity at the time of treatment suspension, especially when measured through C-reactive protein (CRP), as well as age and disease duration [9]. However, the heterogeneity of the clinical symptoms of the AS patients included the different drugs and doses of anti-TNF prescribed prior to the withdrawal of the treatment and especially the lack of homogeneous criteria of clinical remission in the different studies published all mean that the issue remains highly controversial.

More recently, data from a multicenter, randomized, double-blind study in patients with non-radiographic axSpA, who initially achieved sustained remission, showed that continued therapy with adalimumab was associated with a significant maintenance of remission compared with treatment withdrawal [10].

Since anti-TNF treatment also presents drawbacks, such as its high cost and the possibility of long-term side effects, it seems reasonable to plan a time-limited treatment for some patients. The aim of our study was to analyze the consequences of the clinical decision to withdraw anti-TNF treatment in a very homogeneous group of AS patients. In this study, we included only data from AS patients who received infliximab as a first anti-TNF treatment and who presented persistent clinical remission (at least 6 months) in accordance with our pre-established definition [11]. The focus of the study was to assess how long patients maintained a good clinical response defined as the absence of flare after anti-TNF withdrawal, and to define the characteristics of patients who did not present clinical relapse.

\section{Methods}

We conducted a prospective observational study in 23 hospitals with Rheumatology Services in Catalonia, north-eastern Spain, a region with seven million inhabitants. The study included a cohort of patients with active AS who had received infliximab as a first anti-TNF treatment. The study was authorized by the Ethics Committee of the participating hospitals, and all patients gave informed consent prior to taking part in the study.

Patients were included in the cohort and started infliximab treatment if they were aged 18 or over, had a diagnosis of AS according NY criteria, presented a disease duration longer than 1 year, and fulfilled criteria for anti-TNF treatment according to the Guidelines of the Spanish Society of Rheumatology (SER) (BASDAI $\geq 4$, despite treatment with 2 nonsteroidal anti-inflammatory drugs (NSAID) for a minimum of 3 months at full dose) [12]. After the infliximab induction period, all patients who presented persistent clinical remission (BASDAI $\leq$ 2, normal CRP, and absence of active arthritis and/or enthesitis and/or any other extra-articular manifestation during the last 6 months in the absence of any additional steroid and/or NSAID treatment) were included in a prospective study of infliximab withdrawal. Patients with any other definitive diagnosis of spondyloarthritis (psoriatic arthritis, inflammatory bowel disease, or reactive arthritis) were excluded, as were those with any concomitant rheumatic disease that might modify the clinical evaluation of the disease activity.

During the study, in accordance with standard clinical practice, we prospectively recorded the following variables at baseline, and every 6-8 weeks over a follow-up period of 12 months: age, gender, disease duration, the presence and number of peripheral arthritis or enthesitis, the presence of HLA-B27, the BASDAI (Bath Ankylosing Spondylitis Disease Activity Index), CRP, erythrocyte sedimentation rate (ESR), Bath Ankylosing Spondylitis Functional Index (BASFI), and three visual analogue scales (VAS), spine global pain, spinal night time pain, and patient's global assessment. In the pre-study phase, as a secondary objective, we also retrospectively recorded the data from all the cohort of patients with active AS who had initiated treatment with infliximab.

Clinical relapse was defined in any time period as newly appearing BASDAI $\geq 4$ and/or PCR $\geq 0.8 \mathrm{mg} / \mathrm{dl}$. For patients with relapse after treatment withdrawal, infliximab treatment was reintroduced without an induction phase or any previous premedication. At the end, a final visit was performed in all patients included in the study.

Frequencies and percentages were given for subjects who achieved initial remission after infliximab treatment and for subjects who did not present a clinical flare after treatment withdrawal during follow-up. Other parameters including baseline and clinical data during follow-up were described by frequency and percentage, mean and 
standard deviation (SD), median and 25 and 75 percentiles, and $95 \%$ confidence intervals $[95 \% \mathrm{CI}]$, as appropriate. No inferential analysis was conducted.

\section{Results}

One hundred and seven patients, $72 \%$ male, with a first infliximab prescription, were retrospectively identified. The main characteristics of these patients are shown in (Table 1). Among these patients, 36 (34\%) achieved persistent clinical remission and were included in the prospective study, so infliximab treatment was then discontinued. The period of clinical remission before treatment withdrawal ranged in all cases between 6 and 12 months. After treatment withdrawal, only 12 out of these 36 subjects (33.3\%) remained free of clinical relapse during the follow-up. Overall, 21 of these 36 patients $(58.3 \%)$ presented clinical relapse (three patients were lost during the follow-up study). Half of the relapses appeared within 6 months of infliximab withdrawal. In the 21 patients who presented clinical relapse, infliximab therapy was reintroduced and $11(52 \%)$ again achieved clinical remission, but ten (48\%) did not. Of these ten patients, in seven, the reintroduction of infliximab was associated with good clinical response (absence of flare, BASDAI $<4$ and/or CRP $<0.8 \mathrm{mg} / \mathrm{dl}$ ), but in three (14\%), the treatment was ineffective, and we had to change to another anti-TNF treatment (Fig. 1). The reintroduction of infliximab was safe, and no important side effects or infusion reactions were recorded.

Analyzing the retrospective data, we found that age ( $39 \pm 12$ vs $43 \pm 14$ years, $p=0.05)$, disease duration $(9 \pm$ 8 vs $14 \pm 11$ years, $p=0.02$ ), and CRP at the start of infliximab treatment $(3.41 \pm 3.65$ vs $1.63 \pm 2.10, \mathrm{p}=0.02)$ were associated, in the pre-study period, with clinical remission under infliximab treatment. However, unfortunately, we did not find any statistical differences between any clinical or biological parameter in patients who remained free of clinical relapse during follow-up after treatment withdrawal compared with those who did not (Table 2).

\section{Discussion}

This is the first prospective study to show that the majority of longstanding AS patients in persistent clinical remission presented clinical relapse after infliximab withdrawal within the following 12 months. Moreover, although the reintroduction of infliximab was safe and effective in most cases, around half of the patients did not achieve remission after treatment reintroduction and in an additional $10 \%$ the treatment was ineffective, obliging us to change the prescription.

Data from clinical practice and registries have suggested that in patients with sustained clinical remission (i.e., more than 6 months), reducing the treatment dose may be a desirable therapeutic goal [5-7]. For example, the recent EULAR guidelines [13] incorporate the tapering of biological therapy for these patients as a new recommendation, even though the data supporting this policy are limited due to the absence of randomized controlled studies. Recently our group have been communicated a randomized pragmatical study demonstrating the no inferiority of a regime of dose reduction compared with full doses in these patients [14].

Many previous studies have suggested that treatment withdrawal in AS patients leads to a reactivation of the disease [8, 15-17]. Nonetheless, in most studies,

Table 1 Baseline characteristics of the cohort of 107 patients who started infliximab treatment

\begin{tabular}{lll}
\hline & Number of valid values & Baseline characteristics \\
\hline Age (years), mean \pm SD & 104 & $41.8 \pm 12.0$ \\
Disease duration (years) ${ }^{\dagger}$, mean \pm SD & 91,10777 & $11.9 \pm 10.4$ \\
male sex, $n(\%)$ & & $75(70.1 \%)$ \\
HLA-B27 positive, $n(\%)$ & 87 & $69(89.6 \%)$ \\
Modified Schober test $(\mathrm{cm})$, mean \pm SD & 101 & $3.7 \pm 1.9$ \\
Fingertip to floor distance (cm), mean \pm SD & 107 & $19.6 \pm 13.9$ \\
Number of swollen joints, mean \pm SD & 103 & $1.13 \pm 2.2$ \\
CRP (mg/dl), mean \pm SD & 105 & $2.23 \pm 2.82$ \\
ESR (mm/h), mean \pm SD & 99 & $35.3 \pm 28.0$ \\
VAS nocturnal spinal pain (cm), mean \pm SD & 98 & $5.7 \pm 2.8$ \\
VAS spinal pain(cm), mean \pm SD & 99 & $6.3 \pm 2.4$ \\
VAS patient global (cm), mean \pm SD & 102 & $7.2 \pm 1.8$ \\
BASDAl score (cm), mean $\pm S D$ & 100 & $6.2 \pm 1.9$ \\
BASFI score (cm), mean \pm SD & & $4.9 \pm 2.7$
\end{tabular}

$n$ number, $S D$ standard deviation, CRP C-reactive protein, ESR erythrocyte sedimentation rate, VAS patient's rating of pain by visual analogue scale ranging from 0 (none) to 10 (worst), BASDAl Bath Ankylosing Spondylitis Disease Activity Index, BASFI Bath Ankylosing Spondylitis Functional Index

${ }^{\dagger} 50 \%$ of patients had less than 10 years of disease duration 


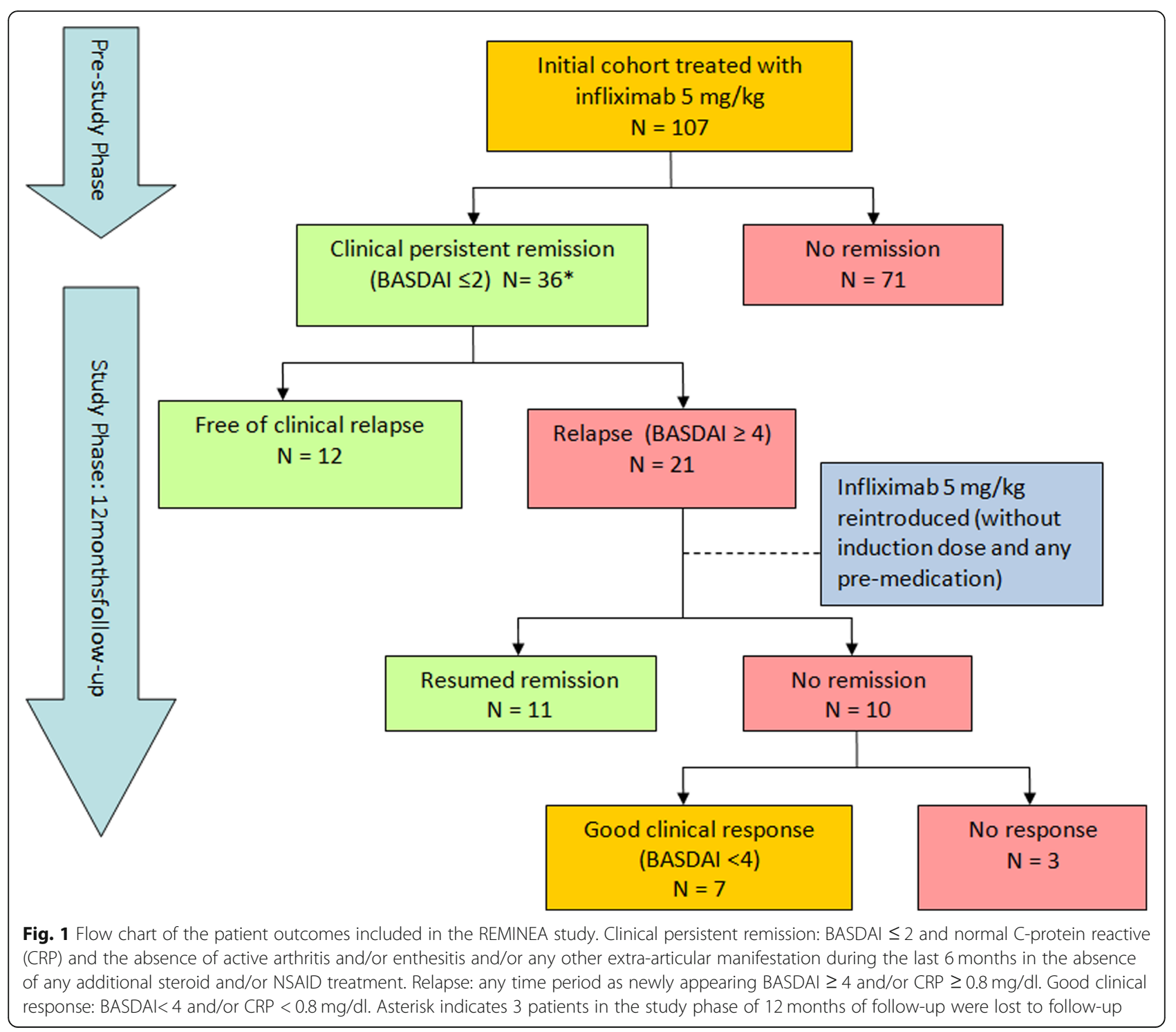

Table 2 Comparison of significant variables between patients on infliximab according to remission status and patients after infliximab withdrawal according to the absence of clinical relapse

\begin{tabular}{|c|c|c|c|c|c|c|}
\hline & \multicolumn{3}{|l|}{ Infliximab treatment } & \multicolumn{3}{|c|}{ Infliximab withdrawal } \\
\hline & $\begin{array}{l}\text { Clinical persistent remission* } \\
(n=36)\end{array}$ & $\begin{array}{l}\text { No remission } \\
(n=71)\end{array}$ & $P$ value & $\begin{array}{l}\text { Clinical relapse** } \\
(n=21)\end{array}$ & $\begin{array}{l}\text { Free of clinical } \\
\text { relapse }(n=12)\end{array}$ & $P$ value \\
\hline Age (years), mean $\pm S D$ & $38.52 \pm 11.96$ & $3.39 \pm 11.81$ & 0.05 & $40 \pm 12$ & $37 \pm 12$ & ns \\
\hline $\begin{array}{l}\text { Disease duration (years)t, } \\
\text { mean } \pm S D\end{array}$ & $8.94 \pm 8.09$ & $13.69 \pm 11.29$ & 0.02 & $9 \pm 8.0$ & $9 \pm 9.0$ & ns \\
\hline $\mathrm{CRP}(\mathrm{mg} / \mathrm{dl})$, mean $\pm \mathrm{SD}$ & $3.41 \pm 3.65$ & $1.63 \pm 2.10$ & 0.01 & $3.9 \pm 3.5$ & $3.0 \pm 3.1$ & ns \\
\hline BASDAI score $(\mathrm{cm})$, mean \pm SD & $5.95 \pm 1.85$ & $6.4 \pm 1.82$ & ns & $6 \pm 2.0$ & $6 \pm 2.0$ & ns \\
\hline BASFI score $(\mathrm{cm})$, mean \pm SD & $4.35 \pm 2.44$ & $5.18 \pm 2.81$ & ns & $4 \pm 3.0$ & $5 \pm 2.0$ & ns \\
\hline
\end{tabular}

SD standard deviation, CRP C-reactive protein, BASDAI Bath Ankylosing Spondylitis Disease Activity Index, BASFI Bath Ankylosing Spondylitis Functional Index ${ }^{*}$ Clinical persistent remission: BASDAI $\leq 2$ and normal C-protein reactive (CRP) and the absence of active arthritis and/or enthesitis and/or any otherextra-articular manifestation during the last 6 months in the absence of any additional steroid and/or NSAID treatment, refers to patients under IFX treatment **Relapse: any time period as newly appearing BASDAl $\geq 4$ and/or CRP $\geq 0.8 \mathrm{mg} / \mathrm{dl}$ after treatment with IFX withdrawal

${ }^{\dagger} 50 \%$ of patients had less than 10 years of disease duration 
withdrawal is performed in patients who are not in clinical remission, and some of them even present high CRP serum levels $[15,16]$. Recently, a controlled and randomized study in non-radiographic axSpA patients reported in patients who achieved sustained remission with adalimumab more reactivation of the disease in the treatment withdrawal compared with the control arm (patients without suspension of anti-TNF) [10]. However, some official recommendations, based only on clinical practice and in the expert opinion, suggest the possibility of withdrawing treatment in AS patients with persistent clinical remission after a notable reduction in anti-TNF therapy $[8,18]$.

The data we reported in AS patients were in agreement with the results previously reported by Landewé et al. in non-radiographic axSpA [10]. Unfortunately, in our study as did Landewé et al., the withdrawn of treatment was performed without dose reduction. However, all the patients previous dose reduction were in persistent remission without any analgesic or anti-inflammatory treatment that could mask the clinical symptoms.

Few studies are focused on the clinical response to re-treatment after withdrawal of anti-TNF therapy in patients with axSpA, suggesting as overall that the reintroduction of treatment is comparable to the previously observed $[15,19,20]$. In contrast, our data indicate that the reintroduction of biological therapy (without previous premedication), although it was safe, only half of the patients achieved clinical remission, as they had before the discontinuation of anti-TNF. These data are in agreement with data recently reported by Landewé et al. in non-radiographic axSpA using adalimumab [10]. Furthermore, in our study, in $10 \%$ of the patients, the re-treatment was ineffective, obliging us to change the anti-TNF therapy.

The patients we included in the study presented definite AS and had received only infliximab treatment as first-line anti-TNF therapy. The baseline characteristics of our patients are quite similar to those in previous studies of anti-TNF therapy $(22,23)$. The baseline clinical characteristics we found to be associated with clinical remission after infliximab treatment-younger age, short disease duration, and high CRP levels-were in agreement with the previously published data [21]. Unfortunately, a complete study of clinical and biological factors associated with the presence of relapse during the following 12 months did not yield any positive results. The sample size of our study seems to be the main factor associated with the negative results observed; however, other larger studies also failed to obtain any results in this regard $[10,20]$.

Overall, the results we reported here suggest that the decision to withdraw treatment should be taken with considerable caution, and it seems unreasonable to propose withdrawal as an objective of the treatment strategy, at least at present, in the absence of any objective predictive factors of persistent clinical remission after treatment withdrawal.

The study has certain limitations that must be mentioned. The sample size is too small to assess factors related to the persistence of remission or the presence of a flare after treatment withdrawal; however, other larger study also failed in this subject [10]. Similarly, since all the patients were in treatment with infliximab, the results need to be corroborated in other anti-TNF agents, but the results published by Landewé et al. [10] using adalimumab are quite similar. Furthermore, our schedule of treatment did not incorporate a strategy of infliximab reduction doses before treatment withdrawal, so we cannot definitively rule out the possibility of withdrawal treatment in patients under persistent remission after intensive doses reduction. The clinical remission period before withdrawal of infliximab treatment (6 to 12 months) does not exclude the possibility of some different results in patients with a longer period of time in clinical remission. Finally, the study began before the publication of the definite new ASAS remission and relapse criteria; however, the criteria applied are widely accepted and used in the clinical practice.

\section{Conclusion}

In summary, this is the first prospective trial performed in a homogeneous cohort of AS patients to evaluate the effect of anti-TNF withdrawal in patients presenting persistent clinical remission. Our data of clinical relapse during the first 12 months in the majority of patients in AS patients are in agreement with the study in non-radiographic axSpA previously published. Moreover, although the reintroduction of infliximab treatment was safe, half of the patients did not achieve the same clinical response as prior to treatment withdrawal.

\section{Abbreviations}

AS: Ankylosing spondylitis; ASAS: Assessment of Spondyloarthritis International Society; AxSpA: Axial spondyloarthritis; BASDAl: Bath Ankylosing Spondylitis Disease Activity Index; BASFl: Bath Ankylosing Spondylitis Functional Index; CRP: C-reactive protein; ESR: Erythrocyte sedimentation rate; IBD: Inflammatory bowel disease; NSAID: Nonsteroidal anti-inflammatory drugs; NY criteria: New York criteria; SD: Standard deviation; SER: Spanish Society of Rheumatology; VAS: Visual analogue scales

\section{Acknowledgements \\ REMINEA study Group}

Arturo Rodriguez-de-la-Serna (Hospital Universitario Santa Creu i Sant Pau, Barcelona), Victoria Hernandez (Hospital Universitario Clínic, Barcelona), Elena Riera (Hospital Universitario Germans Trias i Pujol, Barcelona), Vera Ortiz (Hospital General de Granollers, Barcelona), Teresa Clavaguera (Hospital de Palamós, Girona), Patricia Reyner (Hospital Doctor Josep Trueta, Girona), Miquel Sala (Hospital Figueres, Girona), Agustí Sellas (Hospital Universitario Vall d'Hebron, Barcelona), Concepció Pitarch (Hospital Esperit Sant,

Barcelona), Delia Reina (Hospital Sant Camil, Barcelona), Jordi Blanco (Hospital Sant Jaume de Calella, Barcelona), Montse Centelles (Consorci Sanitari del Maresme, Barcelona), Ramon Figuls (Hospital Dos de Maig, Barcelona), Mario 
Gelman (Hospital Sant Joan de Déu de Manresa, Barcelona), Xavier Arasa (Hospital Tortosa Verge de la Cinta, Tarragona), Maria Bonet (Hospital Comarcal d'Alt Penedès, Barcelona), Manel Ciria (Hospital La Seu d'Urgell, Barcelona).

\section{Funding}

This work is conducted under the umbrella of the Rheumatology Society of Catalonia and supported by Merck Research Laboratories.

\section{Availability of data and materials}

For information of availability of data included in REMINEA database, contact Dr. Juanola.

\section{Declarations}

We confirm that the article has not been published before and is not under consideration for publication elsewhere, and that it is approved by all the authors mentioned.

\section{Authors' contributions}

MM and JG analyzed and wrote the paper; XJ supervised and directed the paper writing; $\mathrm{ML}$ reviewed the paper; $\mathrm{RM}, \mathrm{CP}$, and $\mathrm{VT}$ collected the data and reviewed the database. All authors read and approved the final manuscript.

\section{Ethics approval and consent to participate}

All patients included signed an informed consent to participate in REMINEA and the project was approved by ethical committee of all participant hospitals.

\section{Consent for publication}

Not applicable.

\section{Competing interests}

The authors declare that they have no competing interests.

\section{Publisher's Note}

Springer Nature remains neutral with regard to jurisdictional claims in published maps and institutional affiliations.

\section{Author details}

${ }^{1}$ Rheumatology Department, Parc Taulí Hospital Universitari, I3PT, Universitat Autònoma de Barcelona, 08208 Sabadell, Barcelona, Spain. ${ }^{2}$ Rheumatology Department, Hospital Comarcal de l'Alt Penedès, Vilafranca, Barcelona, Spain. ${ }^{3}$ Rheumatology Department, Hospital Clínic de Barcelona, Universitat de Barcelona, Barcelona, Spain. ${ }^{4}$ Rheumatology Department, Hospital del Vendrell, Tarragona, Spain. ${ }^{5}$ Clinical Pharmacology Department, ParcTaulí Hospital Universitari, I3PT, Universitat Autònoma de Barcelona, Sabadell, Barcelona, Spain. ${ }^{6}$ Rheumatology Department, Hospital Universitari de Bellvitge, IDIBELL, Universitat de Barcelona, L'Hospitalet de Llobregat, Barcelona, Spain.

\section{Received: 27 November 2018 Accepted: 22 March 2019}

\section{Published online: 05 April 2019}

\section{References}

1. Sieper J, Poddubnyy D. Axial spondyloarthritis. Lancet. 2017:390(10089):73-84.

2. Braun J, Pincus T. Mortality, course of disease and prognosis of patients with ankylosing spondylitis. Clin Exp Rheumatol. 2002;20(6 Suppl 28):S16-22.

3. van der Heijde D, Dijkmans B, Geusens P, Sieper J, DeWoody K, Williamson $P$, et al. Efficacy and safety of infliximab in patients with ankylosing spondylitis: results of a randomized, placebo-controlled trial (ASSERT). Arthritis Rheum. 2005;52(2):582-91.

4. Zochling J, Braun J. Remission in ankylosing spondylitis. Clin Exp Rheumatol. 2006;24(6 Suppl 43):S88-92

5. Yates M, Hamilton LE, Elender F, Dean L, Doll H, MacGregor AJ, et al. Is etanercept $25 \mathrm{mg}$ once weekly as effective as $50 \mathrm{mg}$ at maintaining response in patients with ankylosing spondylitis? A randomized control trial. J Rheumatol. 2015;42(7):1177-85.

6. Navarro-Compan V, Moreira V, Ariza-Ariza R, Hernandez-Cruz B, VargasLebron C, Navarro-Sarabia F. Low doses of etanercept can be effective in ankylosing spondylitis patients who achieve remission of the disease. Clin Rheumatol. 2011;30(7):993-6.
7. De Stefano R, Frati E, De Quattro D, Menza L, Manganelli S. Low doses of etanercept can be effective to maintain remission in ankylosing spondylitis patients. Clin Rheumatol. 2014;33(5):707-11.

8. Gonzalez-Alvaro I, Martinez-Fernandez C, Dorantes-Calderon B, Garcia-Vicuna R, Hernandez-Cruz B, Herrero-Ambrosio A, et al. Spanish Rheumatology Society and Hospital Pharmacy Society Consensus on recommendations for biologics optimization in patients with rheumatoid arthritis, ankylosing spondylitis and psoriatic arthritis. Rheumatology (Oxford). 2015;54(7):1200-9.

9. Baraliakos $X$, Listing J, Brandt J, Zink A, Alten R, Burmester G, et al. Clinical response to discontinuation of anti-TNF therapy in patients with ankylosing spondylitis after 3 years of continuous treatment with infliximab. Arthritis Res Ther. 2005;7(3):R439-44.

10. Landewe R, Sieper J, Mease P, Inman RD, Lambert RG, Deodhar A, et al. Efficacy and safety of continuing versus withdrawing adalimumab therapy in maintaining remission in patients with non-radiographic axial spondyloarthritis (ABILITY-3): a multicentre, randomised, double-blind study. Lancet. 2018;392(10142):134-44.

11. Anderson JJ, Baron G, van der Heijde D, Felson DT, Dougados M. Ankylosing spondylitis assessment group preliminary definition of shortterm improvement in ankylosing spondylitis. Arthritis Rheum. 2001;44(8): 1876-86.

12. Mulero J. Primer documento de consenso de la Sociedad Española de Reumatología sobre el uso de antagonistas del TNF-a en las espondiloartritis. Reumatologia clinica. 2005;1(1):32-7.

13. van der Heijde D, Ramiro S, Landewe R, Baraliakos X, Van den Bosch F, Sepriano A, et al. 2016 update of the ASAS-EULAR management recommendations for axial spondyloarthritis. Ann Rheum Dis. 2017;76(6): 978-91.

14. Gratacos J, Pontes C, Juanola X, Sanz J, Torres F, Avendano C, et al. Noninferiority of dose reduction versus standard dosing of TNF-inhibitors in axial spondyloarthritis. Arthritis Res Ther. 2019;21(1):11.

15. Brandt J, Listing J, Haibel H, Sorensen H, Schwebig A, Rudwaleit M, et al. Long-term efficacy and safety of etanercept after readministration in patients with active ankylosing spondylitis. Rheumatology (Oxford). 2005; 44(3):342-8.

16. Brandt J, Haibel H, Cornely D, Golder W, Gonzalez J, Reddig J, et al. Successful treatment of active ankylosing spondylitis with the anti-tumor necrosis factor alpha monoclonal antibody infliximab. Arthritis Rheum. 2000; 43(6):1346-52.

17. Breban M, Vignon E, Claudepierre P, Devauchelle V, Wendling D, Lespessailles $E$, et al. Efficacy of infliximab in refractory ankylosing spondylitis: results of a six-month open-label study. Rheumatology (Oxford). 2002:41(11):1280-5.

18. Gonzalez-Alvaro I, Blasco AJ, Lazaro P, Sanchez-Piedra C, Almodovar R, Bachiller-Corral J, et al. REDOSER project: optimising biological therapy dose for rheumatoid arthritis and spondyloarthritis patients. Heliyon. 2017;3(11): e00452.

19. Baraliakos X, Listing J, Rudwaleit M, Brandt J, Alten R, Burmester G, et al. Safety and efficacy of readministration of infliximab after longterm continuous therapy and withdrawal in patients with ankylosing spondylitis. J Rheumatol. 2007;34(3):510-5.

20. Haibel H, Heldmann F, Braun J, Listing J, Kupper H, Sieper J. Long-term efficacy of adalimumab after drug withdrawal and retreatment in patients with active non-radiographically evident axial spondyloarthritis who experience a flare. Arthritis Rheum. 2013:65(8):2211-3.

21. Baraliakos $X$, Koenig AS, Jones H, Szumski A, Collier D, Bananis E. Predictors of clinical remission under anti-tumor necrosis factor treatment in patients with ankylosing spondylitis: pooled analysis from large randomized clinical trials. J Rheumatol. 2015:42(8):1418-26. 